\title{
Changes in Dissolved Organic Matter during the Treatment Processes of a Drinking Water Plant in Sweden and Formation of Previously Unknown Disinfection Byproducts
}

Michael Gonsior, Philippe Schmitt-Kopplin, Helena Stavklint, Susan D. Richardson, Norbert Hertkorn and David Bastviken

The self-archived postprint version of this journal article is available at Linköping University Institutional Repository (DiVA):

http:// urn.kb.se/ resolve?urn=urn:nbn:se:liu:diva-112812

N.B.: When citing this work, cite the original publication.

Gonsior, M., Schmitt-Kopplin, P., Stavklint, H., Richardson, S. D., Hertkorn, N., Bastviken, D., (2014), Changes in Dissolved Organic Matter during the Treatment Processes of a Drinking Water Plant in Sweden and Formation of Previously Unknown Disinfection Byproducts, Environmental Science and Technology, 48(21), 12714-12722. https:// doi.org/ 10.1021/ es504349p

Original publication available at:

https:// doi.org/ 10.1021/ es504349p

Copyright: American Chemical Society

http:// pubs.acs.org/ 


\section{Dissolved Organic Matter Changes along Treatments of a Drinking Water Plant in Sweden and the Formation of Previously Unknown DBPs}

Michael Gonsior $^{a^{*}}$, Philippe Schmitt-Kopplin ${ }^{b, c}$, Helena Stavklint $^{d}$, Susan D. Richardson ${ }^{e}$, Norbert Hertkorn ${ }^{b}$ and David Bastviken ${ }^{f}$

${ }^{a}$ University of Maryland Center for Environmental Science, Chesapeake Biological Laboratory, Solomons, USA

b Helmholtz Zentrum München, Analytical BioGeoChemistry, Neuherberg, Germany

c Technische Universität München, Analytical Food Chemistry, D-85354 FreisingWeihenstephan, Germany

${ }^{\mathrm{d}}$ Tekniska verken i Linköping AB, Sweden

e University of South Carolina, Department of Chemistry and Biochemistry, Columbia, SC, USA

${ }^{\mathrm{f}}$ Linköping University, Department of Thematic Studies - Environmental Change, Linköping, Sweden

${ }^{*}$ Corresponding author. phone: +14103267245, fax: +14103267302 Email address: gonsior@umces.edu

Keywords: ultrahigh resolution mass spectrometry, FT-ICR-MS, disinfection by-products, DBPs, drinking water treatment, dissolved organic matter, DOM, nuclear magnetic resonance, NMR 


\section{Abstract}

The changes in dissolved organic matter (DOM) throughout the treatment processes in a drinking water treatment plant in Sweden and the formation of disinfection by-products (DBPs) were evaluated by using ultrahigh resolution mass spectrometry (resolution 500,000 at $\mathrm{m} / \mathrm{z} 400$ ) and nuclear magnetic resonance (NMR). Mass spectrometric results revealed that flocculation induced substantial changes in the DOM and caused quantitative removal of DOM constituents that usually are associated with DBP formation. While half of the chromophoric DOM (CDOM) was removed by flocculation, about $4-5 \mathrm{mg} \mathrm{L}^{-1}$ total organic carbon remained in the finished water. A conservative approach revealed the formation of about 800 mass spectrometry ions with unambiguous molecular formula assignments that contained at least one halogen atom. These molecules likely represented new DBPs, which could not be prevented by the flocculation process. The most abundant $\mathrm{m} / \mathrm{z}$ peaks, associated with formed DBPs, could be assigned to $\mathrm{C}_{5} \mathrm{HO}_{3} \mathrm{Cl}_{3}, \mathrm{C}_{5} \mathrm{HO}_{3} \mathrm{Cl}_{2} \mathrm{Br}$ and $\mathrm{C}_{5} \mathrm{HO}_{3} \mathrm{ClBr}_{2}$ by using isotope simulation patterns with the likely DBPs were produced and suggested the presence of halogenated polyphenolic and aromatic acidtype structures, which was supported by possible structures that matched the lower molecular mass range (max. 10 carbon atoms) of these DBPs. ${ }^{1} \mathrm{H}-\mathrm{NMR}$ before and after disinfection revealed about a $2 \%$ change of the overall ${ }^{1} \mathrm{H}$-NMR signals supporting a significant change of the DOM caused by disinfection. This study underlines that a large and increasing number of people are exposed to a very diverse pool of organohalogens through water - by both drinking and uptake through the skin upon contact. Non-target analytical approaches are indispensable to reveal the magnitude of this exposure and to test alternative ways to reduce it. 


\section{Introduction}

Disinfection of drinking water is widely implemented to avert diseases by infectious water-borne pathogens. Disinfection is accomplished with strong oxidants, such as free chlorine, chlorine dioxide, chloramines and ozone, which efficiently kill pathogens. It was not until the 1970s when the first group of disinfection by-products (DBPs) were discovered [1] and related to adverse health effects (i.e., cancer) [2]. These secondary chemicals are formed by the reaction of the disinfectant with natural dissolved organic matter (DOM) or other micro-pollutants, such as bromide and iodide.

Since that time, a wealth of information has been produced about DBPs and their toxicity, including cytotoxicity, genotoxicity, and adverse birth outcomes [3-17]. More than 600 DBPs have now been identified [9]. However, about a 50\% decrease of free chlorine ( $\mathrm{HOCl})$ remains unaccounted for during drinking water treatment and cannot be entirely explained by known DBPs [11, 18]. It has long been suggested that free chlorine gets incorporated into high molecular weight DOM, and early research on molecular size fractions indicated that more than $50 \%$ of the total organic halogen formed in chlorinated drinking water is greater than $1000 \mathrm{Da}$ [19-21]. Recent research using ultrahigh resolution mass spectrometry, which has the ability to track the incorporation of chlorine in extremely complex mixtures of organic molecules in drinking water, confirmed the presence of high molecular weight chlorinated DBPs [22, 23], although all ions found were well below $1000 \mathrm{Da}$. This discrepancy between the earlier membrane fractionation experiments and the more recent ultrahigh resolution mass spectrometry experiments may be due to the fact that not covalently bound aggregates remain intact during membrane size fractionations, but separate in electrospray ionization with ultrahigh resolution mass spectrometry. A previous suggestion that multiply charged ions are responsible for the 
much lower mass range observed in mass spectrometry when compared to size exclusion chromatography interfaced with ultraviolet detectors [24] can be ruled out, because of the very precise measurements of masses in this study that have an error much less than the mass of an electron. Here, multiply-charged ions, which occupy the space in-between nominal mass clusters of singly charged ions, were largely absent.

A large number of DBPs have been identified, but the abundance, exposure, and toxicity of these complex mixtures are only slowly emerging. Despite the expected complex formation mechanisms of DBPs, the United States and Europe regularly monitor only three classes: trihalomethanes (THMs), haloacetic acids (HAAs) and oxyhalides (bromate and chlorite) [25, 26]. Our knowledge about DBP toxicity and abundance thus remains limited. Notably, the extensive molecular diversity of DBPs makes it very difficult to identify specific toxic DBPs.

Disinfection is expected to become more important in the future, due to climate change with accompanying increasing temperatures and prolonged warm seasons, which will likely yield higher amounts of waterborne pathogens, particularly in temperate or boreal regions that traditionally had very limited water borne illnesses recorded in the past. Sweden is such an example with $50 \%$ of its drinking water coming from surface water sources. In this context, proper assessments of DBP exposure are increasingly important. To what extent removal of DOM before disinfection also removes DBP precursors is critical. Such tests are rare because of difficulties to investigate complex DBP-mixtures incorporated into the large molecular diversity of DOM. The main objective of this study was to follow the complex mixture of DOM entering a water treatment plant throughout the different treatment processes and to characterize the complex pool of DBPs formed. Known classes of DBPs such as HAAs or THMs are either 
outside of the mass window or not retained by the solid phase extraction used in this study and therefore were not evaluated in this study.

\section{Methods}

Sampling and solid phase extraction (SPE) of DOM. All water samples were collected at the Råberga water treatment plant located in Linköping, Sweden at the same time in august 2011. This plant is a prime example for smaller scale water treatment that faces the challenges in controlling and maintaining high water quality standards. The raw water intake is $2.5 \mathrm{~m}$ below the surface of the Stångån River. The water is pumped through a grid into the chemical precipitation unit, which consists of three parallel assemblies, each consisting of a stirred flocculation tank and a three-story sedimentation tank. Aluminum sulfate is used as a flocculant, supplemented with sodium silicate as a flocculation aid. The water passes then through six rapid sand filters at a filter speed of $4-8 \mathrm{~m}^{3} \mathrm{~h}^{-1}$ for particle removal. The $\mathrm{pH}$ is adjusted to $\mathrm{pH} 8.4$ with sodium hydroxide before the water is pumped to eight slow sand filters, which have a total area of 5,440 $\mathrm{m}^{2}$ and a filter rate of 0.13 to $0.26 \mathrm{~m}^{3} \mathrm{~h}^{-1}$. Further, water $\mathrm{pH}$ adjustments are achieved by adding sodium hydroxide. The final step is disinfection with sodium hypochlorite ( $\mathrm{NaOCl})$. The annual average concentration of total chlorine before distribution was $0.36 \mathrm{mg} \mathrm{L}^{-1}$. The mixed water is stored in reservoirs totaling $11,000 \mathrm{~m}^{3}$ before the water is distributed. The treatment plant is designed to produce $10,000 \mathrm{~m}^{3}$ per day. The Stångån River has relatively high total organic carbon (TOC) concentrations (10-12 $\left.\mathrm{mg} \mathrm{L}^{-1}\right)$ and a flocculation treatment was necessary to reduce the CDOM and to reduce the TOC. The treatment plant regularly measured TOC and the variation of TOC in the raw and processed waters between 2011 and 2013 is given in Supporting Information (Fig. S1). The TOC of the raw water averaged $10 \mathrm{mg} \mathrm{L}^{-1}$. Flocculation 
removed about half of the TOC and finished water still contained 4-5 mg L-1. Taste and odor problems occurred occasionally and the treatment plant is undergoing major upgrades in 2014.

Duplicate samples of $2 \mathrm{~L}$ raw water (intake), $5 \mathrm{~L}$ water after flocculation, $5 \mathrm{~L}$ after rapid sand filtration, $5 \mathrm{~L}$ after slow sand filtration and $5 \mathrm{~L}$ after disinfection were collected in acid-base cleaned glass bottles. Immediately after collection, all samples were filtered through precombusted Whatman GF/F glass fiber filters and no quenching agents were added to the disinfected water to avoid any additional sources of contamination. The $\mathrm{pH}$ was adjusted to 2 using high purity grade formic acid (98\%). This step was necessary to enhance the SPE efficiency to about 60\% dissolved organic carbon (DOC) using Agilent Bond Elut PPL SPE cartridges filled with $1 \mathrm{~g}$ of highly functionalized styrene-divinylbenzene (SDVB) polymer that has been modified with a proprietary non-polar surface. The SPE method has been previously described [27], but we modified it by replacing concentrated $\mathrm{HCl}$ with concentrated formic acid to avoid any sampling bias of chloride ions in the methanolic eluent. Chloride ions are problematic, because even at relatively low concentrations, DOM may form chloride adducts that could be mistaken for covalently bound DBPs and were even used as a dopant to analyze saccharides [28]. No chloride adducts were formed in samples collected prior to disinfection in this study confirming the effectiveness using formic acid instead of $\mathrm{HCl}$ to avoid adduct formations. The SPE cartridge was activated using methanol (Sigma-Aldrich Chromasolv LCMS grade methanol), washed with acidified ( $\mathrm{pH}$ 2) high purity water (Sigma-Aldrich Chromasolv LC-MS grade water). Then, the acidified sample was gravity-fed through the SPE cartridge at a flow rate of $10 \mathrm{~mL} / \mathrm{min}$. The cartridge was washed again with acidified pure water to replace the last remaining inorganic ions from the SPE cartridge. After washing, the cartridge was dried under high purity grade nitrogen gas and eluted with $10 \mathrm{~mL}$ methanol. The extraction 
efficiency ranged for all samples between 52-59\% without any observed trends between the treatment trains. Limitation of this SPE method include the loss of practically all highly volatile DBPs and DOM compounds due to the drying procedure of the SPE resin prior to elution with methanol and the loss of about $40 \%$ of DOC during extraction.

Total organic carbon measurements. TOC was measured at the treatment plant and is part of a routine measurement using an Analytik Jena multi C/N 3100 analyzer with high temperature combustion.

Ultrahigh resolution mass spectrometry. Ultrahigh resolution mass spectrometry was applied to characterize the DOM and formed DBPs using a Bruker Apex QE 12 Tesla Fourier transform (FT) ion cyclotron resonance (ICR) mass spectrometer interfaced with negative ion mode electrospray ionization (ESI'). Positive ESI $\left(\mathrm{ESI}^{+}\right)$was not used in this study due to sodium adduct formation and much more complicated procedures to accurately assign molecular formulas, especially with the presence of high abundant isotopomers of chlorine and bromine. It is recognized here that it is likely that DBPs are missed that only ionize in $\mathrm{ESI}^{+}$.

The spray current was set to $-3.6 \mathrm{kV}$ and the methanolic DOM sample was diluted with methanol at a ratio of 1:40 to obtain optimum transient spectra, which was necessary to avoid an overload of the ICR cell and the potential occurrence of peak splitting or other interferences between ions. The flow rate was set to $3 \mu \mathrm{L} \min ^{-1}$ and 750 scans were acquired for each spectrum. The injection lines were washed with $600 \mu \mathrm{L}$ (80\% methanol, 20\% water) between each sample to avoid cross-contamination and a carryover of samples from previous runs. Blank methanol samples were run every 5 samples and data confirmed that no carryover occurred.

This instrument achieved excellent sensitivity (mass accuracy $<0.2 \mathrm{ppm}$ error after internal calibration with ubiquitous fatty acids) and yielded information about molecular ions 
related to unambiguous molecular formula assignments. New custom-developed molecular formula assignment software developed at the Helmholtz Center for Environmental Health, Munich, Germany has largely automated the post processing of FT-ICR-MS data based on the following chemical elements: ${ }^{12} \mathrm{C}_{0-\infty},{ }^{1} \mathrm{H}_{0-\infty},{ }^{16} \mathrm{O}_{0-\infty},{ }^{14} \mathrm{~N}_{0-5}{ }^{32} \mathrm{~S}_{0-2,}{ }^{35} \mathrm{Cl}_{0-3}$ and ${ }^{79} \mathrm{Br}_{0-3}$ isotopes, as well as the ${ }^{13} \mathrm{C},{ }^{34} \mathrm{~S},{ }^{37} \mathrm{Cl}$, and ${ }^{81} \mathrm{Br}$ isotopes. A detailed description of how to unambiguously assign molecular formulas to FT-ICR-MS data was given previously [29]. To achieve the highest degree of mass accuracy, a post calibration with known mass peaks of DOM and there exact masses and assigned molecular formulas was used throughout the observed $m / z$ range $(m / z$ 150800) [30, 31]. Van Krevelen diagrams [30-37] and modified Kendrick plots [36, 38] were previously utilized to visualize FT-ICR-MS data and were also used in this study. Briefly, in a van Krevelen diagram, the elemental ratios of hydrogen to carbon (H/C) versus oxygen to carbon (O/C) of all assigned molecular formulas are plotted. This plot allows evaluating of relative hydrogen deficiency or oxygen deficiency of the assigned molecular formulas and visualizes the "chemical space” occupied by any given sample. The modified Kendrick plot is a plot, where homologous series of assigned molecular formulas, which are spaced by $\mathrm{CH}_{2}$, can be easily depicted along the observed $\mathrm{m} / \mathrm{z}$ range. The foundation of this modified Kendrick plot is based on the Kendrick Mass Defect (KMD) and another independent homologous series parameter referred to as $z^{*}$. These parameters were previously defined and explained in detail [39].

Statistical analysis. To statistically compare in detail measured mass spectra, all $\mathrm{m} / \mathrm{z}$ lists, including the associated intensities were combined in a single matrix, which was normalized using a logarithmic transformation to avoid single high intensity ions to unproportionally contribute to dissimilarities. Simple hierarchical cluster analyses were performed to evaluate whether or not significant differences existed between sample sets and duplicates. The Bray 
Curtis similarity approach [40] with logarithmically transformed data was a robust and reliable way to show similarities between datasets and was chosen in this study.

Nuclear magnetic resonance spectroscopy. NMR spectroscopy offers quantitative depiction of compositional and structural alterations of DOM and was applied to the characterization of Råberga DOM before and after disinfection with hypochlorite. NMR spectra of solid-phase extracted DOM were acquired immediately after sample preparation with a Bruker Avance III NMR spectrometer operating at $500.13 \mathrm{MHz}$ for ${ }^{1} \mathrm{H}$ with a $5 \mathrm{~mm}$ z-gradient dual ${ }^{13} \mathrm{C} /{ }^{1} \mathrm{H}$ cryogenic probe in ${ }^{12} \mathrm{CD}_{3} \mathrm{OD}\left(99.8 \%{ }^{2} \mathrm{H} ;<0.05 \%{ }^{13} \mathrm{C}\right.$; Aldrich, Steinheim, Germany) and $3.0 \mathrm{~mm}$ Bruker MATCH NMR tubes. ${ }^{1} \mathrm{H}$ NMR chemical shift references were $\mathrm{HD}_{2} \mathrm{OD}$ : 3.30 ppm and ${ }^{12} \mathrm{CD}_{3} \mathrm{OD}: 49.00 \mathrm{ppm}$. All spectra were acquired with TopSpin 3.2/PL3 software at 283 $\mathrm{K}$ and acquisition parameters matched those previously used [41] and are provided in the Supporting Information (Tab. S1).

\section{Results and Discussion}

Ultrahigh resolution mass spectra revealed detailed changes in the DOM pool during water treatments in the treatment plant (Fig. 1). Statistical evaluation using hierarchical cluster analysis revealed significant differences between the DOM in the intake, after flocculation, and after disinfection with hypochlorite (Fig. 2). A direct comparison between intake water SPEDOM and final product water DOM showed substantial differences in the molecular composition at each nominal mass (NM), with a large contribution of newly formed chlorinated DBPs (Fig. 1).

Flocculation did change the DOM drastically, with large shifts in relative abundances across the entire pool of DOM. These changes are visualized using van Krevelen or elemental 
plots before and after flocculation (Fig. 3). The presumably polyphenolic-like DOM (e.g. tannins, lignins, etc.), including CDOM, were preferentially removed by flocculation (Fig. 3), which was indicated by the removal of compounds with rather low $\mathrm{H} / \mathrm{C}$ ratios (0.4-1.2) and medium to high $\mathrm{O} / \mathrm{C}$ ratios (0.5-0.9). The rank correlated molecular ions that highly correlated with humic-like fluorescent peaks in a previous study [42] were similar to the ions removed by flocculation in this study and hence support the assumption that the removed molecular ions are part of the CDOM pool.

The disinfection step induced the largest changes in the molecular composition of DOM (Figs. 1, 2 and 4). Even though flocculation substantially removed DOM components, it did not prevent the formation of DBPs, presumably due to the relatively high levels of remaining TOC that were less effectively removed by flocculation. In fact, a large number ( 800) of $\mathrm{m} / \mathrm{z}$ peaks that were unambiguously assigned to molecular formulas with one, two or three chlorine atoms were formed during disinfection (Fig. 4). This is a conservative approach and only ions that showed a relative abundance of more than $0.2 \%$ were included. In general, chlorine- or brominecontaining molecular formulas can be confirmed using isotope simulation because of the high abundance of their higher mass isotopes ${ }^{37} \mathrm{Cl}$ (37\%) and ${ }^{81} \mathrm{Br}(49 \%)$ and respective distinctive isotope patterns. Only two brominated ions were confirmed with a threshold of $0.2 \%$ of relative abundance. The evaluation of homologous series (molecular formulas that have a spacing of $\mathrm{CH}_{2}$-groups) revealed the systematic formation of DBP homologous series throughout the observed mass range between 200 and $600 \mathrm{Da}$ (Fig. 4).

We also discovered three highly abundant DBPs and isotopic simulation confirmed the correct molecular formula assignment and these DBPs may have been observed previously as possible drinking water related DBPs, but at much less mass resolution without the capability to 
assign exact molecular formulas [43]. The molecular formulas of this specific class of DBPs (with pronounced unsaturation and absence of hydrogen) and the low carbon number implied very limited isomeric possibilities (Fig. 5). Given the constraints of FT-ICR-MS in determining exact isotope ratios, the isotope simulation matched the expected pattern of suggested molecular formulas and the only plausible structures for these compounds were either halogenated furoic acids: trichloro furoic acid, dichloro-bromo furoic acid and dibromo-chloro furoic acid or their 2,2,4-trihalo-5-hydroxy-4-cyclopentene-1,3-dione analogues (Fig. 5). The rel. abundances of trichloro, dichloro-bromo and dibromo-chloro compounds were $2.1 \%, 2.26 \%$ and $0.67 \%$, respectively. The increased abundance of the dichloro-bromo compounds when compared to trichloro compounds was at first surprising given the fact that other brominated DBPs were very low and consequently the rel. abundance should drastically decrease with increasing number of bromine atoms. However, given the fact that the ion guide frequencies cannot be optimized for any given mass ion, the low mass ions were likely to be much less efficiently transported to the ICR cell with the settings used and would mean that rel. abundances of low molecular weight ions are somewhat lower than they should be if ion guides would have been optimized for lower masses. This suggestion is supported by the rel. abundance of DOM ions in comparison to the halogenated furoic acids or 2,2,4-trihalo-5-hydroxy-4-cyclopentene-1,3-diones (trihaloHCDs) (NM: 213, 257 and 301) and the ratio of these halogenated compounds to the maximum abundant DOM ions at that NM. It can be clearly seen in Figure 5 that the peak height of the halogenated furoic acids or trihaloHCDs relative to the peak heights of DOM ions was dramatically decreasing with increasing number of bromine atoms, which was expected and which was not contradicting the low abundance of other brominated DBPs, but it nevertheless underlined the rel. high abundance of these halogenated furoic acids or trihaloHCDs. Bromide 
was not measured during this study, which makes it difficult to evaluate the production of brominated DBPs.

At present, it is not clear to what extent the two abundant classes of compounds (trihalofuroic acids or trihaloHCDs) are present in our samples, but a recent study points towards trihalo HCDs [17]. These authors confirmed the structure of ion clusters similar to the ones found in this study by using MS fragmentation patterns and concluded that the molecular formulas of $\mathrm{C}_{5} \mathrm{HO}_{3} \mathrm{Cl}_{2} \mathrm{Br}$ and $\mathrm{C}_{5} \mathrm{HO}_{3} \mathrm{ClBr}_{2}$ corresponded to 2,2,4-dichlorobromo-5-hydroxy-4cyclopentene-1,3-dione and 2,2,4-dibromochloro-5-hydroxy-4-cyclopentene-1,3-dione, respectively. These trihaloHCDs appear to further react quickly with additional free chlorine to form HAAs and THMs [43], hence can be considered to be intermediate DBPs. Their reactivity is of great concern and may well play an important role in toxicological effects.

In addition to the trihaloHCDs, a large group of halogenated low molecular weight assigned formulas (less than 10 carbon atoms) were remarkably similar, and their H/C and O/C ratios suggested a polyphenol-type or aromatic acid-type structure, indicating another class of DBPs. We explored this possibility and we could find plausible, mainly hydroxyphenolic and aromatic acids for formulas with less than 10 carbon atoms (Tab. 1). Higher molecular weight molecules of assigned formulas may also represent this polyphenolic/aromatic acid class but opportunities to form isomeric structures increase rapidly with increasing weight, and hence, we chose only to give compound examples of formulas that contained less than 10 carbon atoms. Even formulas with 10 carbon atoms have already a large number of chemically reasonable isomeric structures and the given polyphenolic/aromatic acids (Tab. 1) are only intended as guidance of which type of molecules may be halogenated. However, it is chemically sound that 
polyphenolic and aromatic acids are susceptible to halogenation, as has been demonstrated in previous studies [17, 43-46].

The hierarchical cluster analysis of all DOM samples throughout the treatment process, in tandem with a large chemical diversity of DBPs found, indicated a significant transformation of DOM during disinfection and supported earlier findings of a complex mixture of non-volatile DBPs $[22,23,46]$ that are formed during disinfection. The majority of these DBPs are likely the product of the reaction of $\mathrm{HOCl}$ with aromatic polyphenolic-type compounds. Earlier research has shown that humic and fulvic acids, which constitute a large component of the DOM in natural waters, are composed of polyphenolic structures [47]. We could not confirm brominated DBPs beside the above mentioned trihaloHCDs, and this is likely due to a very low abundance of brominated DBPs. A few potential brominated compounds were found, but they did not exceed $0.2 \%$ relative abundance and isotope simulation was not conclusive at their low abundance.

Overall, ${ }^{1} \mathrm{H}$ and ${ }^{13} \mathrm{C}$ NMR spectra looked rather unchanged before and after chlorination, suggesting minor overall alterations of DOM chemistry (Supporting Information: Tabs. S1 and S2). This is consistent with bulk total organic halogen (TOX) measurements (representing total chloro-, bromo-, and iodo-DBPs) observed for chlorinated water, in which only a low percentage of TOX is formed compared to the initial non-halogenated DOM. For example, in the U.S. Nationwide Occurrence Study, a median level of $178 \mu \mathrm{g} \mathrm{L}^{-1}$ levels of TOX was formed from a median level of $5.8 \mathrm{mg} \mathrm{L}^{-1}\left(5800 \mu \mathrm{g} \mathrm{L}^{-1}\right)$ of TOC with the use of chorine and other disinfectants [18].

Difference ${ }^{1} \mathrm{H}$ NMR spectroscopy and NMR spectral editing did reveal a molecular variance of DOM as a consequence of chlorination (Fig. 6). New, weak but rather sharp NMR resonances appeared in DOM following chlorination, testifying to the presence of distinct 
molecules which were formed during chlorination. Overall, the NMR integral of ${ }^{1} \mathrm{H}$ NMR resonances ranged below 2\%, implying that the bulk DOM characteristics still dominated over newly formed molecules (similar to earlier TOX measurements mentioned above [48]). Chlorination led to a relative increase of functionalized aliphatic units (i. e. $\underline{\mathbf{H C C X}}$ units; $\delta_{\mathrm{H}}: 1.8$ - $2.9 \mathrm{ppm})$ and a marked AA`B-multiplet structure $\left(\delta_{\mathrm{H}}=3.510 \mathrm{ppm}: 2 \mathrm{H}, \mathrm{dd}, \mathrm{J}=11.2,6.0 \mathrm{~Hz} ; \delta_{\mathrm{H}}\right.$ = $3.582 \mathrm{ppm} ; 2 \mathrm{H}, \mathrm{dd}, \mathrm{J}=11.2,4.8 \mathrm{~Hz} ; \delta_{\mathrm{H}}=3.652 \mathrm{ppm}: 1 \mathrm{H}$, pentett, $\mathrm{J}=5.5 \mathrm{~Hz}$ ). The abundance of compounds resonating in the section of esters and other highly oxygenated aliphatic compounds also increased in abundance $\left(\delta_{\mathrm{H}}>4\right)$. However, this section of the difference NMR spectrum may also represent newly formed chlorinated aliphatic compounds and might also become affected from differential solvent suppression in both DOM samples. Nevertheless, tiny newly formed NMR resonances remained visible. Olefins $\left(\delta_{\mathrm{H}}: 5.15-6.1 \mathrm{ppm}\right)$ as well as some neutral and oxygenated aromatics or halogenated aromatics $\left(\delta_{\mathrm{H}}>7.05 \mathrm{ppm}\right)$ increased in abundance after chlorination. In contrast, pure aliphatic compounds (i.e. $\underline{\mathbf{H}} \mathrm{C}_{\mathrm{n}} \mathrm{C}$ units; $\mathrm{n}>2 ; \delta_{\mathrm{H}}<$ $1.9 \mathrm{ppm}$ ), methoxy groups in various chemical environments as well as possibly carbohydrates

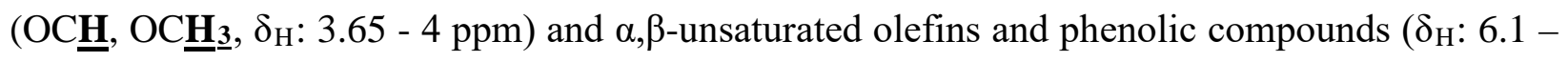
$7.05 \mathrm{ppm}$ ) decreased in abundance during chlorination. The decrease in OC$\underline{\mathbf{H}}$ of phenols is consistent with an increase in chlorinated phenols as suggested by the FT-MS data. Chlorination of unsaturated bonds $(=\mathrm{CH})$ and the formation of $=\mathrm{C}-\mathrm{Cl}$ moieties which resonate in this section of proton NMR chemical shift was likely to interfere with this basic interpretation. Alternatively, aliphatic $\underline{\mathbf{H} C C l}$-units will resonate near $\delta_{\mathrm{H}}=5.6 \mathrm{ppm}$; i.e. in the nominal ${ }^{1} \mathrm{H}$ NMR chemical shift section of $\mathrm{O}_{2} \mathrm{C} \underline{\mathbf{H}}$ and $=\mathrm{C} \underline{\mathbf{H}}$ groups. The addition of a chlorine atom to organic molecules causes in general a rather large shift $\left(\sim 3 \delta_{\mathrm{H}}\right)$ and is likely to be responsible for the apparent 
increase in hydrogens associated with aromatic $\left(\mathrm{H}_{\mathrm{ar}}\right)$ and hydrogens in other unsaturated compounds $(\underline{\mathbf{H}} \mathrm{C}=\mathrm{C})$ (Tab. S1) and complicating the analysis of ${ }^{1} \mathrm{H}$ NMR section integrals.

Difference NMR spectra of single pulse ${ }^{13} \mathrm{C}$ NMR spectra showed an insufficient S/N ratio for allowing unambiguous conclusions about structural alterations initiated by chlorination. However, the abundance of methoxy groups declined visibly (Supporting Information: Fig. S2 and Tab. S3). Further research is needed to more precisely determine the precursors of DBP formation, and it can be envisioned that bulk parameters, such as measurements of total phenolic content [49] may help to predict DBP formation.

By using new advanced technologies, such as ultrahigh resolution non-target analyses, this study revealed a large number of new and potentially important DBPs. Our study illustrates that humans may be exposed to a complex mixture of DBPs of unknown structure and toxicity. The large number of halogenated ions found in this study and the much larger number of unknown but potentially synergistic biological effects pose an important human health challenge in preventing DBP formation while guarantee efficient disinfection.

Non-target ultrahigh resolution techniques have demonstrated the importance to reveal the magnitude of DBP formation and a possible next step forward is to further constrain the classes of DBPs that are formed and link these with DOM precursors. One way to achieve further separation and information of polarity-based classes of DBP compounds is the implementation of liquid chromatography-based separation prior to ultrahigh resolution mass spectrometry. Modern ultrahigh pressure liquid chromatography (UPLC) and complementary stationary phases (e.g. reversed phase versus amino based) could drastically constrain classes of newly discovered DBPs, prior to FT-MS analysis. 


\section{Acknowledgements}

The advanced analytical instrumentation located at the Helmholtz Center for Environmental Health in Munich, Germany, enabled critical non-target organic structural spectroscopy. This study was financially supported by the Swedish Research Council FORMAS (Grant 2013-1077). We also thank Tekniska Verken, Linköping for cooperation and data sharing. This is contribution XXXX from the University of Maryland Center for Environmental Science, Chesapeake Biological Laboratory.

\section{Supporting Information Available}

The supporting information includes tables and details about ${ }^{1} \mathrm{H}$ and ${ }^{13} \mathrm{C}-\mathrm{NMR}$ cross section integrals of DOM before and after disinfection (Tab. S1 and S2), a figure about TOC concentrations measured betwee 2011-2013 (Fig. S1), as well as the ${ }^{13}$ C-NMR spectra before and after disinfection (Fig. S2). These are the tables and figures referred to in the main text. The supporting information is available free of charge via the Internet at http://pubs.acs.org/ 


\section{References}

1. Rook, J. J., Formation of haloforms during chlorination of natural waters. Water Treatment Examination 1974, (23), 234-243.

2. National Cancer Institute Report On Carcinogenesis Bioassay of Chloroform (CAS No. 67-66-3); National Cancer Institute: Bethesda, MD, 1976.

3. Bull, R. J.; Reckhow, D. A.; Li, X.; Humpage, A. R.; Joll, C.; Hrudey, S. E., Potential carcinogenic hazards of non-regulated disinfection by-products: haloquinones, halo-cyclopentene and cyclohexene derivatives, N-halamines, halonitriles, and heterocyclic amines. Toxicology 2011, 286, (1-3), 1-19.

4. $\quad$ Costet, N.; Garlantezec, R.; Monfort, C.; Rouget, F.; Gagniere, B.; Chevrier, C.; Cordier, S., Environmental and Urinary Markers of Prenatal Exposure to Drinking Water Disinfection By-Products, Fetal Growth, and Duration of Gestation in the PELAGIE Birth Cohort (Brittany, France, 2002-2006). American Journal of Epidemiology 2012, 175, (4), 263-275.

5. Ding, G.; Zhang, X., A Picture of Polar Iodinated Disinfection Byproducts in Drinking Water by (UPLC/)ESI-tqMS. Environ. Sci. Technol. 2009, 43, (24), 9287-9293.

6. Grazuleviciene, R.; Nieuwenhuijsen, M. J.; Vencloviene, J.; Kostopoulou-Karadanelli, M.; Krasner, S. W.; Danileviciute, A.; Balcius, G.; Kapustinskiene, V., Individual exposures to drinking water trihalomethanes, low birth weight and small for gestational age risk: a prospective Kaunas cohort study. Environmental Health 2011, 10.

7. Nieuwenhuijsen, M. J.; Toledano, M. B.; Eaton, N. E.; Fawell, J.; Elliott, P., Chlorination disinfection byproducts in water and their association with adverse reproductive outcomes: a review. Occupational and Environmental Medicine 2000, 57, (2), 73-85.

8. Richardson, S. D.; Ternes, T. A., Water Analysis: Emerging Contaminants and Current Issues. Analytical chemistry 2014, 86, (6), 2813-2848.

9. Richardson, S. D., Disinfection By-Products: Formation and Occurrence in Drinking Water. In Encyclopedia of Environmental Health, Nriagu, J., Ed. Elsevier Science: Burlington, 2011; pp 110-136.

10. Richardson, S. D.; Nriagu, J. O., The Encyclopedia of Environmental Health. 2011; Vol. 2, p 110.

11. Richardson, S. D.; Plewa, M. J.; Wagner, E. D.; Schoeny, R.; DeMarini, D. M., Occurrence, genotoxicity, and carcinogenicity of regulated and emerging disinfection byproducts in drinking water: A review and roadmap for research. Mutation Research-Reviews in Mutation Research 2007, 636, (1-3), 178-242.

12. Savitz, D. A.; Singer, P. C.; Herring, A. H.; Hartmann, K. E.; Weinberg, H. S.; Makarushka, C., Exposure to drinking water disinfection by-products and pregnancy loss. American Journal of Epidemiology 2006, 164, (11), 1043-1051.

13. Villanueva, C. M.; Gracia-Lavedan, E.; Ibarluzea, J.; Santa Marina, L.; Ballester, F.; Llop, S.; Tardon, A.; Fernandez, M. F.; Freire, C.; Goni, F.; Basagana, X.; Kogevinas, M.; Grimalt, J. O.; Sunyer, J.; Infancia, I.; Medio, A., Exposure to Trihalomethanes through Different Water Uses and Birth Weight, Small for Gestational Age, and Preterm Delivery in Spain. Environmental Health Perspectives 2011, 119, (12), 1824-1830.

14. Villanueva, C. M.; Cantor, K. P.; Cordier, S.; Jaakkola, J. J. K.; King, W. D.; Lynch, C. F.; Porru, S.; Kogevinas, M., Disinfection byproducts and bladder cancer - A pooled analysis. Epidemiology 2004, 15, (3), 357-367. 
15. Waller, K.; Swan, S. H.; DeLorenze, G.; Hopkins, B., Trihalomethanes in drinking water and spontaneous abortion. Epidemiology 1998, 9, (2), 134-140.

16. Waller, K.; Swan, S. H.; Windham, S. C.; Fenster, L., Influence of exposure assessment methods on risk estimates in an epidemiologic study of total trihalomethane exposure and spontaneous abortion. Journal of Exposure Analysis and Environmental Epidemiology 2001, 11, (6), 522-531.

17. Zhai, H.; Zhang, X.; Zhu, X.; Liu, J.; Ji, M., Formation of Brominated Disinfection Byproducts during Chloramination of Drinking Water: New Polar Species and Overall Kinetics. Environ. Sci. Technol. 2014, 48, (5), 2579-2588.

18. Krasner, S. W.; Weinberg, H. S.; Richardson, S. D.; Pastor, S. J.; Chinn, R.; Sclimenti, M. J.; Onstad, G. D.; Thruston, A. D., Occurrence of a New Generation of Disinfection Byproducts $\dagger$. Environ. Sci. Technol. 2006, 40, (23), 7175-7185.

19. Khiari, D.; Krasner, S. W.; Hwang, C. J.; Chinn, R.; Barrett, S. In Effects of Chlorination and Chloramination on the Molecular Weight Distribution of Natural Organic Matter and the Production of High-Molecular-Weight Disinfection By-Products, AWWA Water Technology Conference, Boston, MA, 1996; American Water Works Association: Boston, MA, 1996.

20. Zhang, X.; Minear, R. A., Characterization of High Molecular Weight Disinfection Byproducts Resulting from Chlorination of Aquatic Humic Substances. Environmental Science \& Technology 2002, 36, (19), 4033-4038.

21. Zhang, X.; Minear, R. A., Formation, adsorption and separation of high molecular weight disinfection byproducts resulting from chlorination of aquatic humic substances. Water Research 2006, 40, (2), 221-230.

22. Lavonen, E. E.; Gonsior, M.; Tranvik, L. J.; Schmitt-Kopplin, P.; Köhler, S. J., Selective Chlorination of Natural Organic Matter: Identification of Previously Unknown Disinfection Byproducts. Environ. Sci. Technol. 2013, 47, (5), 2264-2271.

23. Z Zhang, H.; Zhang, Y.; Shi, Q.; Hu, J.; Chu, M.; Yu, J.; Yang, M., Study on Transformation of Natural Organic Matter in Source Water during Chlorination and Its Chlorinated Products using Ultrahigh Resolution Mass Spectrometry. Environ. Sci. Technol. 2012, 46, (8), 4396-4402.

24. Zhang, X.; Minear, R. A.; Barrett, S. E., Characterization of High Molecular Weight Disinfection Byproducts from Chlorination of Humic Substances with/without Coagulation Pretreatment Using UF-SEC-ESI-MS/MS. Environmental Science \& Technology 2005, 39, (4), 963-972.

25. U.S. Environmental Protection Agency, National Primary Drinking Water Regulations: Stage 2 Disinfectants and Disinfection Byproducts Rule. In Federal Register: 2006; Vol. 71, p 388.

26. The Council of the European Union, COUNCIL DIRECTIVE 98/83/EC of 3 November 1998 on the quality of water intended for human consumption. In Official Journal of the European Communities: 1998; p L 330/32.

27. Dittmar, T.; Koch, B.; Hertkorn, N.; Kattner, G., A simple and efficient method for the solid-phase extraction of dissolved organic matter (SPE-DOM) from seawater. Limnol. Oceanogr.: Methods 2008, 6, (June), 230-235.

28. Boutegrabet, L.; Kanawati, B.; Gebefügi, I.; Peyron, D.; Cayot, P.; Gougeon, R. D.; Schmitt-Kopplin , P., Attachment of Chloride Anion to Sugars: Mechanistic Investigation and Discovery of a New Dopant for Efficient Sugar Ionization/Detection in Mass Spectrometers. Chemistry - A European Journal 2012, 18, (41), 13059-13067. 
29. Koch, B. P.; Dittmar, T.; Witt, M.; Kattner, G., Fundamentals of molecular formula assignment to ultrahigh resolution mass data of natural organic matter. Analytical chemistry 2007, 79, (4), 1758-63.

30. Gonsior, M.; Peake, B. M.; Cooper, W. T.; Podgorski, D.; D'Andrilli, J.; Cooper, W. J., Photochemically Induced Changes in Dissolved Organic Matter Identified by Ultrahigh Resolution Fourier Transform Ion Cyclotron Resonance Mass Spectrometry. Environ. Sci. Technol. 2009, 43, 698-703.

31. Gonsior, M.; Peake, B. M.; Cooper, W. T.; Podgorski, D. C.; D'Andrilli, J.; Dittmar, T.; Cooper, W. J., Characterization of dissolved organic matter across the Subtropical Convergence off the South Island, New Zealand. Marine Chemistry 2011, 123, (1-4), 99-110.

32. Kim, S.; Kramer, R. W.; Hatcher, P. G., Graphical Method for Analysis of UltrahighResolution Broadband Mass Spectra of Natural Organic Matter, the Van Krevelen Diagram. Anal. Chem. 2003, 75, (20), 5336-5344.

33. Hertkorn, N.; Frommberger, M.; Witt, M.; Koch, B.; Schmitt-Kopplin, P.; Perdue, E. M., Natural Organic Matter and the Event Horizon of Mass Spectrometry. Analytical Chemistry 2008, 80, (23), 8908-8919.

34. Dittmar, T., The molecular level determination of black carbon in marine dissolved organic matter. Org. Geochem. 2008, 39, (Copyright (C) 2011 American Chemical Society (ACS). All Rights Reserved.), 396-407.

35. $\quad$ Flerus, R.; Lechtenfeld, O. J.; Koch, B. P.; McCallister, S. L.; Schmitt-Kopplin, P.; Benner, R.; Kaiser, K.; Kattner, G., A molecular perspective on the ageing of marine dissolved organic matter. Biogeosciences 2012, 9, (6), 1935-1955.

36. Gonsior, M.; Schmitt-Kopplin, P.; Bastviken, D., Depth-dependent molecular composition and photo-reactivity of dissolved organic matter in a boreal lake under winter and summer conditions. Biogeosciences 2013, 10, (11), 6945-6956.

37. Sleighter, R. L.; Hatcher, P. G., Molecular characterization of dissolved organic matter (DOM) along a river to ocean transect of the lower Chesapeake Bay by ultrahigh resolution electrospray ionization Fourier transform ion cyclotron resonance mass spectrometry. Mar. Chem. 2008, 110, (3-4), 140-152.

38. Shakeri Yekta, S.; Gonsior, M.; Schmitt-Kopplin, P.; Svensson, B. H., Characterization of Dissolved Organic Matter in Full Scale Continuous Stirred Tank Biogas Reactors Using Ultrahigh Resolution Mass Spectrometry: A Qualitative Overview. Environ. Sci. Technol. 2012, 46, (22), 12711-12719.

39. Stenson, A. C.; Marshall, A. G.; Cooper, W. T., Exact Masses and Chemical Formulas of Individual Suwannee River Fulvic Acids from Ultrahigh Resolution Electrospray Ionization Fourier Transform Ion Cyclotron Resonance Mass Spectra. Anal. Chem. 2003, 75, (6), 12751284.

40. Bray, J. R.; Curtis, J. T., An Ordination of the Upland Forest Communities of Southern Wisconsin. Ecological Monographs 1957, 27, (4), 325-349.

41. Gonsior, M.; Hertkorn, N.; Conte, M. H.; Cooper, W. J.; Bastviken, D.; Druffel, E.; Schmitt-Kopplin, P., Photochemical production of polyols arising from significant phototransformation of dissolved organic matter in the oligotrophic surface ocean. Marine Chemistry 2014, 163, (0), 10-18.

42. $\quad$ Herzsprung, P.; von Tümpling, W.; Hertkorn, N.; Harir, M.; Büttner, O.; Bravidor, J.; Friese, K.; Schmitt-Kopplin, P., Variations of DOM Quality in Inflows of a Drinking Water 
Reservoir: Linking of van Krevelen Diagrams with EEMF Spectra by Rank Correlation. Environ. Sci. Technol. 2012, 46, (10), 5511-5518.

43. Zhai, H.; Zhang, X., Formation and Decomposition of New and Unknown Polar Brominated Disinfection Byproducts during Chlorination. Environ. Sci. Technol. 2011, 45, (6), 2194-2201.

44. Gallard, H.; von Gunten, U., Chlorination of Phenols: Kinetics and Formation of Chloroform. Environ. Sci. Technol. 2002, 36, (5), 884-890.

45. Rebenne, L. M.; Gonzalez, A. C.; Olson, T. M., Aqueous Chlorination Kinetics and Mechanism of Substituted Dihydroxybenzenes. Environ. Sci. Technol. 1996, 30, (7), 2235-2242.

46. Pan, Y.; Zhang, X., Four Groups of New Aromatic Halogenated Disinfection Byproducts: Effect of Bromide Concentration on Their Formation and Speciation in Chlorinated Drinking Water. Environ. Sci. Technol. 2013, 47, (3), 1265-1273.

47. Thurman, E. M., Organic Geochemistry of Natural Waters. Martinus Nijhoff/Dr. W. Junk Publishers: Dordrecht, 1985; Vol. 2.

48. $\quad$ Chai, W.-M.; Liu, X.; Hu, Y.-H.; Feng, H.-L.; Jia, Y.-L.; Guo, Y.-J.; Zhou, H.-T.; Chen, Q.-X., Antityrosinase and antimicrobial activities of furfuryl alcohol, furfural and furoic acid. International Journal of Biological Macromolecules 2013, 57, (0), 151-155.

49. Takeda, K.; Moriki, M.; Oshiro, W.; Sakugawa, H., Determination of phenolic concentrations in dissolved organic matter pre-concentrate using solid phase extraction from natural water. Marine Chemistry 2013, 157, 208-215. 
Table 1: FT-MS results of the most intense DBP-related ions, as well as DBP ions that contain 10 or less carbon atoms and have a mass lower than $240 \mathrm{Da}$. Theoretical examples of polyphenolic and aromatic acids that match the assigned molecular formulas are also shown. Note: All formulas were confirmed by isotopic simulation and the presence of the ${ }^{37} \mathrm{Cl}$, and if applicable, the ${ }^{81} \mathrm{Br}$ isotope.

\begin{tabular}{|c|c|c|c|c|c|c|c|c|c|}
\hline Most abundant DBPs & $\begin{array}{l}\text { Mass measured } \\
(\mathrm{M}-\mathrm{H})^{-}\end{array}$ & $\begin{array}{l}\text { Intensity } \\
\text { (TIC) }\end{array}$ & $\begin{array}{l}\text { Exact Mass } \\
\text { (neutral) }\end{array}$ & $\begin{array}{c}\text { Molecular } \\
\text { Formula (M) }\end{array}$ & KMD & $\mathrm{O} / \mathrm{C}$ & $\mathbf{H} / \mathbf{C}$ & DBE & DBE/C \\
\hline $\begin{array}{l}\text { 2,2,4-trichloro-5-hydroxy-4-cyclopentene- } \\
\text { 1,3-dione }\end{array}$ & 212.89195 & 73570248 & 213.89913 & $\mathrm{C} 5 \mathrm{HO} 3 \mathrm{Cl} 3$ & 0.340 & 0.600 & 0.200 & 4 & 0.800 \\
\hline $\begin{array}{l}\text { 2,2,4-dichlorobromo-5-hydroxy-4- } \\
\text { cyclopentene-1,3-dione }\end{array}$ & 256.84130 & 79120600 & 257.84861 & $\mathrm{C} 5 \mathrm{HO} 3 \mathrm{Cl} 2 \mathrm{Br}$ & 0.439 & 0.600 & 0.200 & 4 & 0.800 \\
\hline $\begin{array}{l}\text { 2,2,4-chlorodibromo-5-hydroxy-4- } \\
\text { cyclopentene-1,3-dione }\end{array}$ & 300.79090 & 23593458 & 301.79810 & C5HO3ClBr2 & 0.539 & 0.600 & 0.200 & 4 & 0.800 \\
\hline \multicolumn{10}{|l|}{$\begin{array}{l}\text { Possible chlorinated polyphenolic and } \\
\text { aromatic acids }\end{array}$} \\
\hline chlorophthalic acid & 198.98044 & 5253117 & 199.98763 & C8H5O4Cl1 & 0.236 & 0.500 & 0.625 & 6 & 0.750 \\
\hline chlorophloretic acid & 199.01677 & 5412670 & 200.02402 & C9H9O3Cl1 & 0.199 & 0.333 & 1.000 & 5 & 0.556 \\
\hline chloro-orsellinic acid & 200.99595 & 8649003 & 202.00329 & C8H7O4Cl1 & 0.222 & 0.500 & 0.875 & 5 & 0.625 \\
\hline dichloro-orsellinic acid & 234.95704 & 10247170 & 235.96432 & $\mathrm{C} 8 \mathrm{H} 6 \mathrm{O} 4 \mathrm{Cl} 2$ & 0.299 & 0.500 & 0.750 & 5 & 0.625 \\
\hline chlorogallic acid & 202.97535 & 6198405 & 203.98255 & C7H5O5Cl1 & 0.245 & 0.714 & 0.714 & 5 & 0.714 \\
\hline dichlorogallic acid & 236.93641 & 7044813 & 237.94358 & $\mathrm{C} 7 \mathrm{H} 4 \mathrm{O} 5 \mathrm{Cl} 2$ & 0.322 & 0.714 & 0.571 & 5 & 0.714 \\
\hline chloromethoxyphenylacrylic acid & 211.01672 & 5943678 & 212.02402 & C10H9O3Cl1 & 0.213 & 0.300 & 0.900 & 6 & 0.600 \\
\hline chlorodihydroxycinnamic acid & 212.99611 & 11082396 & 214.00329 & C9H7O4Cl1 & 0.236 & 0.444 & 0.778 & 6 & 0.667 \\
\hline chloromethoxyhydrocinnamic acid & 213.03239 & 6392293 & 214.03967 & C10H11O3Cl1 & 0.199 & 0.300 & 1.100 & 5 & 0.500 \\
\hline chlorohydroxyphthalic acid & 214.97521 & 11232844 & 215.98255 & C8H5O5Cl1 & 0.259 & 0.625 & 0.625 & 6 & 0.750 \\
\hline chlorodimethoxybenzoic acid & 215.01169 & 12298902 & 216.01899 & C9H9O4Cl1 & 0.222 & 0.444 & 1.000 & 5 & 0.556 \\
\hline chlorodihydroxymandelic acid & 216.99100 & 10869836 & 217.99820 & C8H7O5Cl1 & 0.245 & 0.625 & 0.875 & 5 & 0.625 \\
\hline dichlorohydroxyphenylacetic acid & 218.96214 & 5940199 & 219.96940 & C8H6O3Cl2 & 0.276 & 0.375 & 0.750 & 5 & 0.625 \\
\hline dichlorodihydroxybenzoic acid & 220.94148 & 10401146 & 221.94867 & $\mathrm{C} 7 \mathrm{H} 4 \mathrm{O} 4 \mathrm{Cl} 2$ & 0.299 & 0.571 & 0.571 & 5 & 0.714 \\
\hline chlorodihydroxy-naphthoquinone & 222.98040 & 10615130 & 223.98764 & C10H5O4Cl1 & 0.262 & 0.400 & 0.500 & 8 & 0.800 \\
\hline chloroscopoletin & 224.99606 & 9621716 & 226.00329 & C10H7O4Cl1 & 0.249 & 0.400 & 0.700 & 7 & 0.700 \\
\hline chlorocarboxycarbonylbenzoic acid & 226.97526 & 13598656 & 227.98255 & C9H5O5Cl1 & 0.272 & 0.556 & 0.556 & 7 & 0.778 \\
\hline chloroferulic acid & 227.01175 & 14956549 & 228.01894 & C10H9O4Cl1 & 0.236 & 0.400 & 0.900 & 6 & 0.600 \\
\hline chloromethoxyphthalic acid & 228.99103 & 16821404 & 229.99820 & C9H7O5Cl1 & 0.259 & 0.556 & 0.778 & 6 & 0.667 \\
\hline chlorosyringic acid & 231.00666 & 19996432 & 232.01385 & C9H9O5Cl1 & 0.245 & 0.556 & 1.000 & 5 & 0.556 \\
\hline
\end{tabular}




\begin{tabular}{|l|c|c|c|c|c|c|c|c|c|}
\hline chlorotrihydroxy-methoxybenzoic acid & 232.98589 & 6958285 & 233.99312 & C8H7O6Cl1 & 0.268 & 0.750 & 0.875 & 5 & 0.625 \\
\hline
\end{tabular}

O $\mathrm{O} / \mathrm{C}=$ oxygen to carbon ratio; $\mathrm{H} / \mathrm{C}=$ hydrogen to carbon ratio; $\mathrm{DBE}=$ Double Bond Equivalency; $\mathrm{DBE} / \mathrm{C}=$ Double Bond Equivalency divided by carbon number 


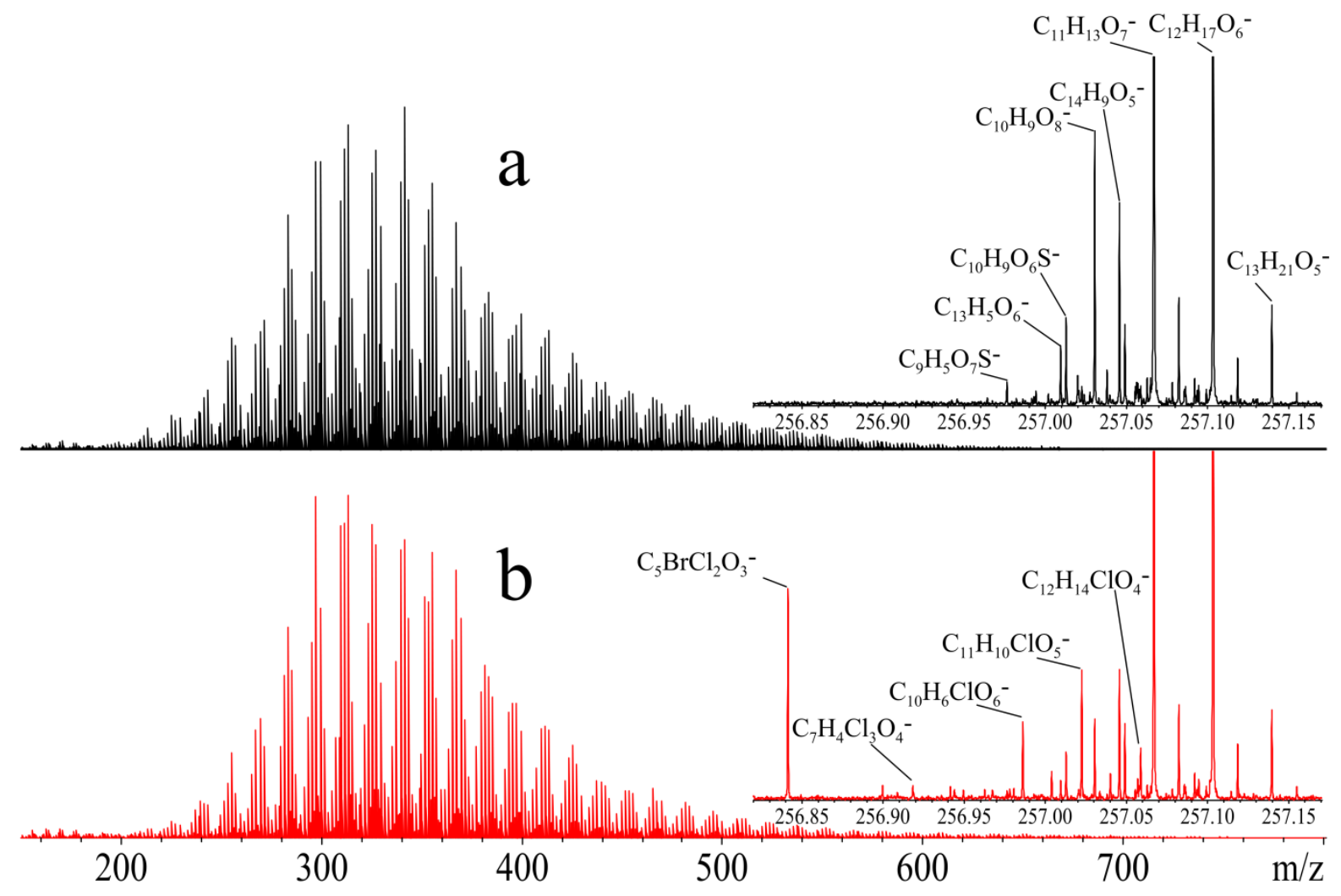

Figure 1: Ultrahigh resolution mass spectra of raw water DOM (a) and after disinfection (b), including the molecular formula assignments of major ions at NM 257. 


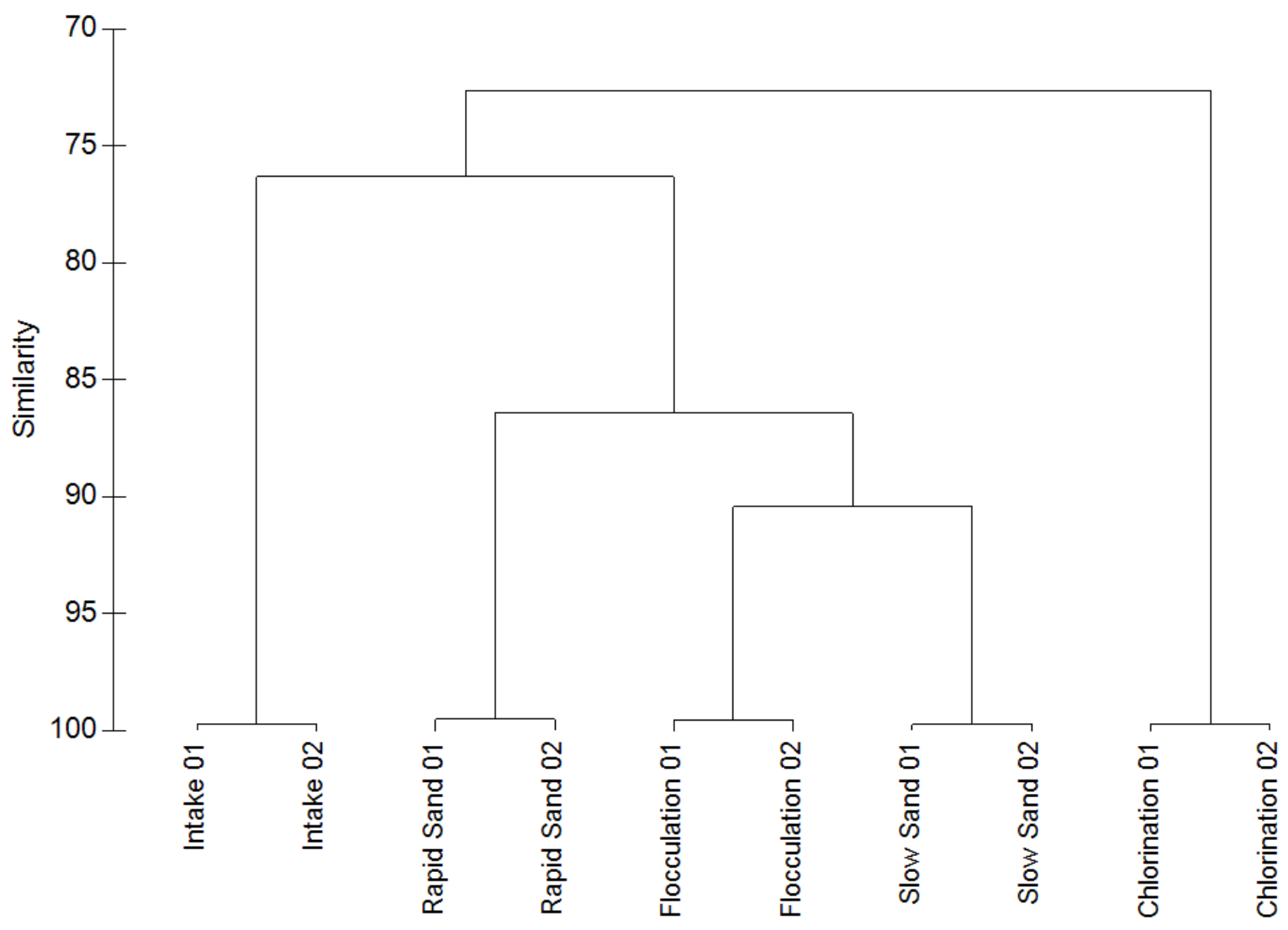

Figure 2: Hierarchical cluster analysis of duplicate sampling throughout the different water treatments. Note: The FT-ICR-MS data was logarithmically transformed prior to Bray Curtis Similarity resemblance calculations. 

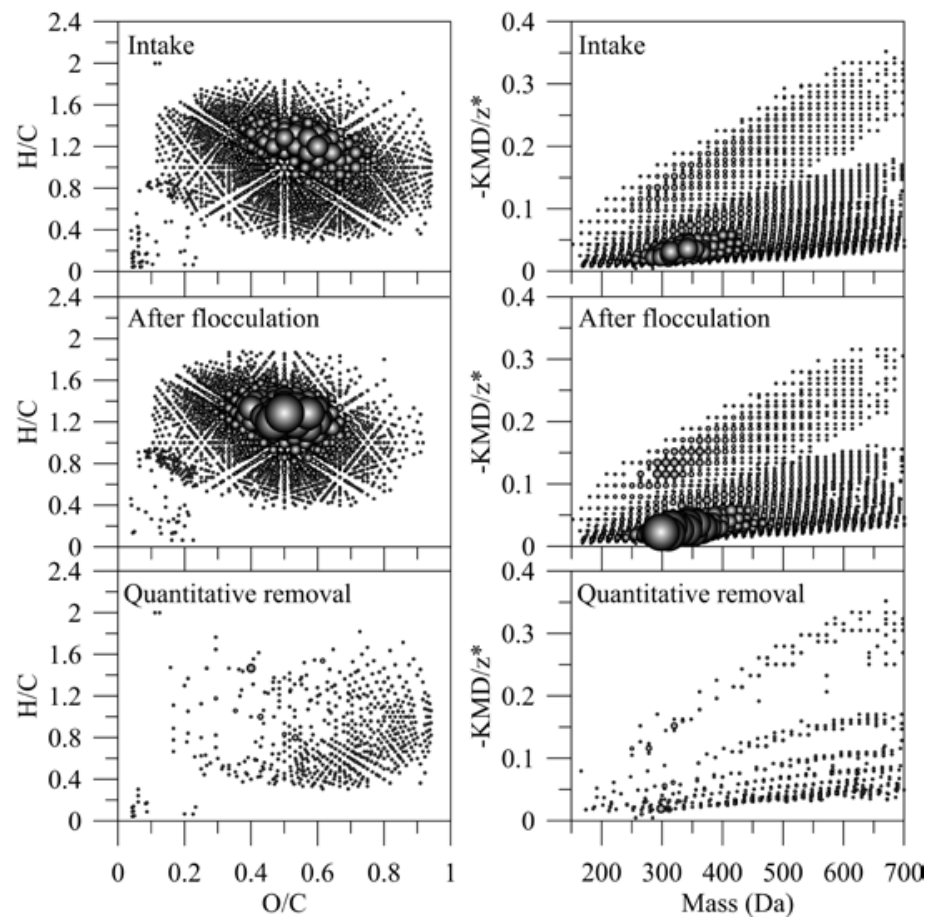

Figure 3: Van Krevelen diagrams and modified Kendrick plots (-KMD/z* versus mass) of the DOM of the raw water (intake), after flocculation and the removal of many polyphenolic-type ions and associated molecular formulas during the flocculation treatment. Note: The modified Kendrick plot (-KMD/z* versus mass) was previously described in detail [38]. The bubble areas represent the relative abundance of ions. 

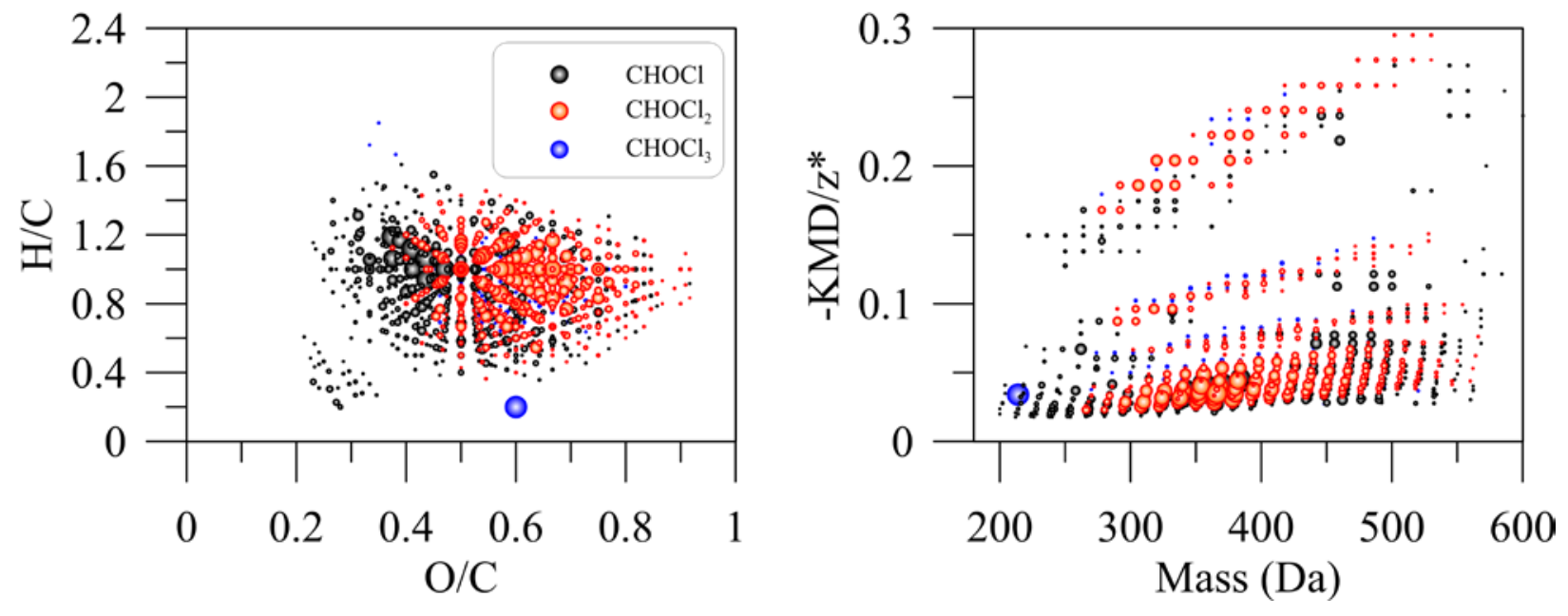

Figure 4: Production of DBPs during the disinfection by using hypochlorite and visualized using a van Krevelen and modified Kendrick plot. The bubble areas represent the relative abundance of ions. 


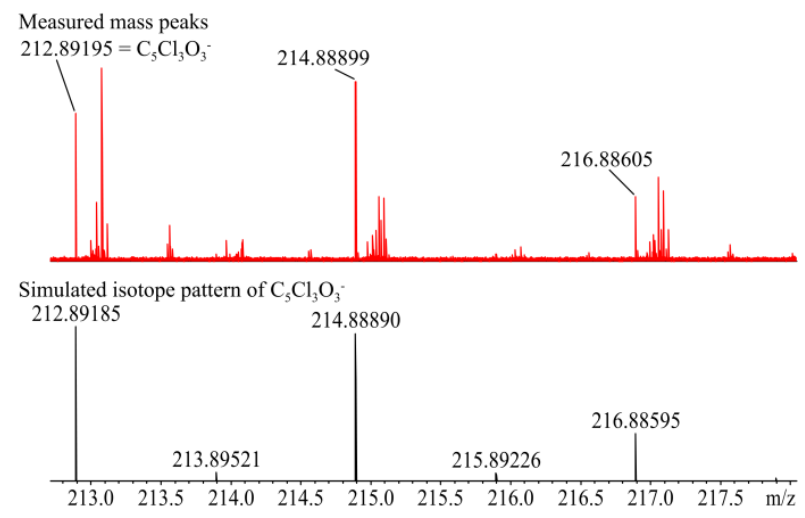<smiles>O=C(O)c1oc(Cl)c(Cl)c1Cl</smiles>

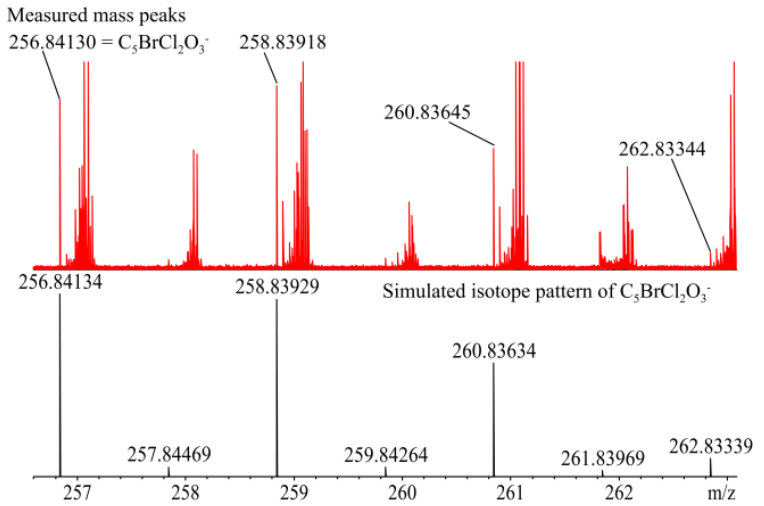<smiles>O=C1C(Cl)=C(O)C(O)C1(Cl)Br</smiles><smiles>O=C(O)c1oc(Cl)c(Cl)c1Br</smiles>

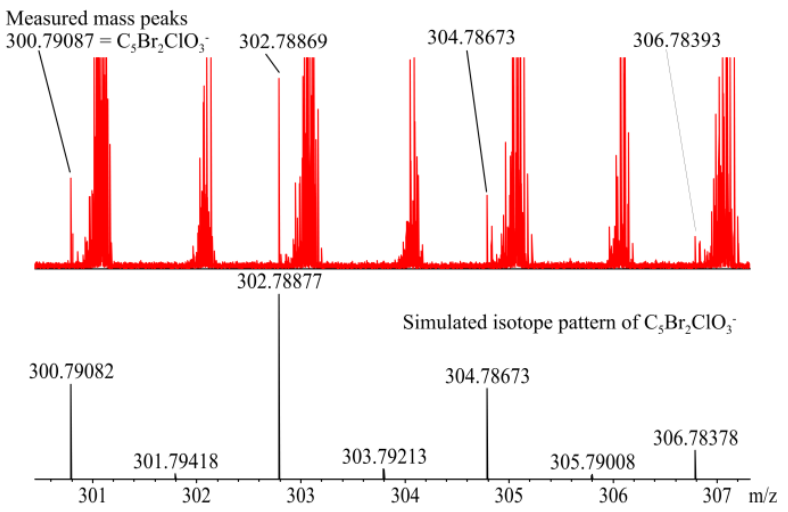<smiles>O=C(O)c1oc(Cl)c(Br)c1Br</smiles>

Figure 5: Some relatively high abundant ions with a large mass defect indicated the presence of halogenated compounds. The molecular formulas of these ions were confirmed by isotopic simulation and only two isomers are likely being either 2,2,4-trihalo-5-hydroxy-4-cyclopentene1,3-diones or trihalofuroic acids. 


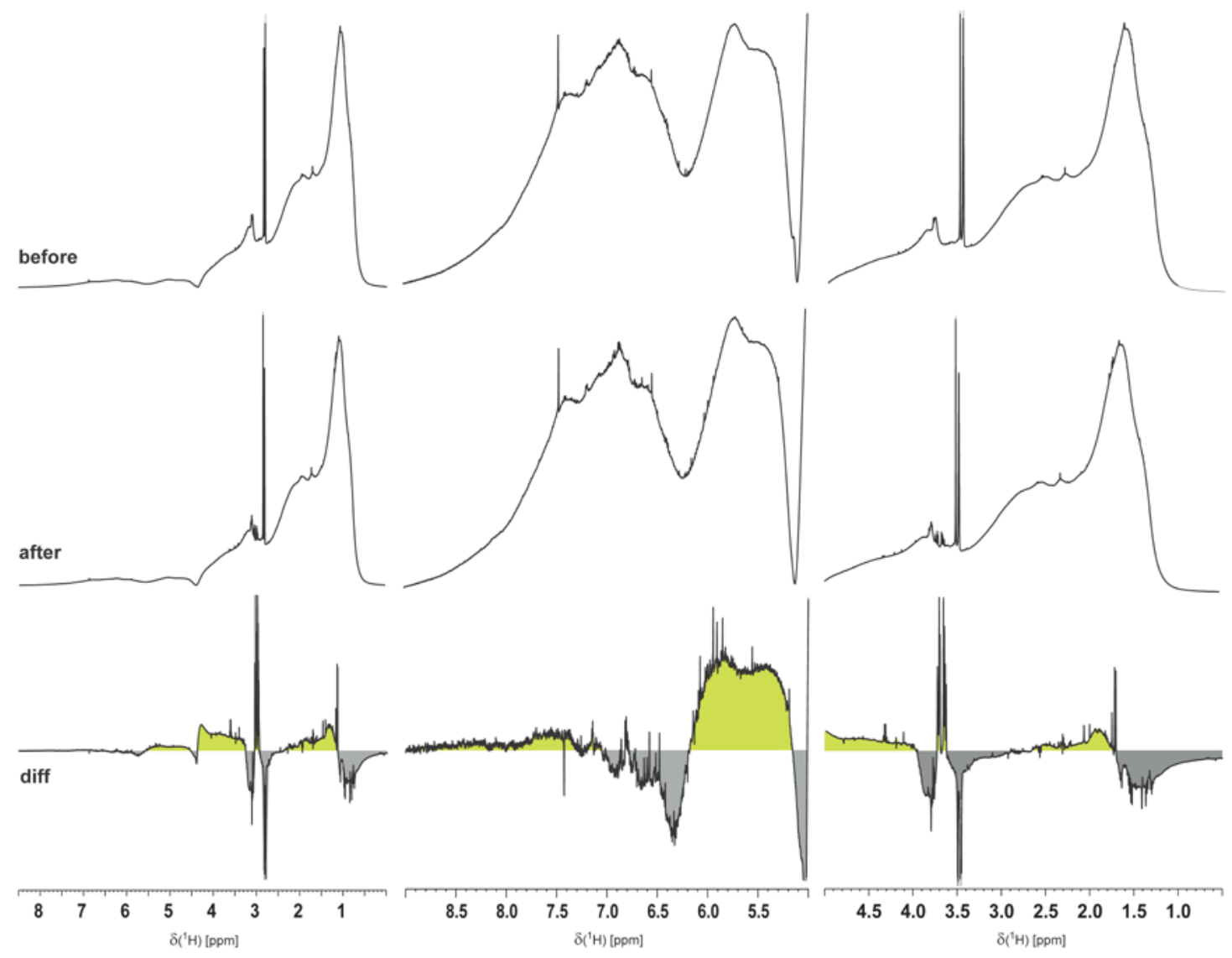

Figure 6: $1 \mathrm{H}$ NMR spectra of DOM (12CD3OD solution, $500 \mathrm{MHz}$ ) before (top) and after (middle) chlorination; bottom row: difference NMR spectrum with green: DOM features increased in relative abundance after chlorination, and gray: DOM features decreased in relative abundance after chlorination. 


\title{
Supplementary Information
}

\section{Changes in Dissolved Organic Matter during the Treatment Processes of a Drinking Water Plant in Sweden and Formation of Previously Unknown Disinfection Byproducts}

\author{
Michael Gonsior ${ }^{a^{*}}$, Philippe Schmitt-Kopplin ${ }^{b, c}$, Helena Stavklint ${ }^{d}$, Susan D. Richardson ${ }^{e}$, \\ Norbert Hertkorn ${ }^{b}$ and David Bastviken ${ }^{f}$
}

${ }^{a}$ Chesapeake Biological Laboratory , University of Maryland Center for Environmental Science, Solomons, USA

${ }^{\mathrm{b}}$ Helmholtz Zentrum München, Analytical BioGeoChemistry, Neuherberg, Germany

${ }^{\mathrm{c}}$ Technische Universität München, Analytical Food Chemistry, D-85354 FreisingWeihenstephan, Germany

${ }^{\mathrm{d}}$ Tekniska verken i Linköping AB, Sweden

${ }^{\mathrm{e}}$ University of South Carolina, Department of Chemistry and Biochemistry, Columbia, SC, USA

${ }^{\mathrm{f}}$ Linköping University, Department of Thematic Studies - Environmental Change, Linköping, Sweden

${ }^{*}$ Corresponding author. phone: +14103267245, fax: +14103267302, Email address: gonsior@umces.edu

\section{Summary}

Table S1

Table S2

Page S2

Table S3

Page S3

Figure S1

Page S4

Figure S2

Page S5

Page S6 


\begin{tabular}{|c|c|c|c|c|c|c|}
\hline spectrum & Figure & NS & AQ [s] & D1 [s] & WDW2 & PR2 \\
\hline $\begin{array}{c}{ }^{1} \mathrm{H} \text { NMR } \\
\text { before / after Cl }\end{array}$ & 6 & 512 & 5 & 5 & $\mathrm{EM}$ & 1 \\
\hline $\begin{array}{c}{ }^{13} \mathrm{C} \mathrm{NMR} \\
\text { before / after Cl }\end{array}$ & $\mathrm{S} 2$ & $9361 / 9456$ & 1 & 19 & $\mathrm{EM}$ & $35(2)$ \\
\hline $\begin{array}{c}\mathrm{DEPT} 45 / 135{ }^{13} \mathrm{C} \mathrm{NMR} \\
\text { before } / \text { after Cl }\end{array}$ & $\mathrm{S} 2$ & 16384 & 1 & 2 & $\mathrm{EM}$ & 12.5 \\
\hline $\begin{array}{c}\text { DEPT } 90{ }^{13} \mathrm{C} \mathrm{NMR} \\
\text { before / after Cl }\end{array}$ & $\mathrm{S} 2$ & 32768 & 1 & 2 & $\mathrm{EM}$ & 12.5 \\
\hline
\end{tabular}

Table S1: Acquisition parameters of NMR spectra, shown according to figures. NS: number of scans (for 2D NMR: F2); AQ: acquisition time [ms]; D1: relaxation delay [ms]; NE: number of F1 increments in 2D NMR spectra; WDW1, WDW2: apodization functions in F1/ F2 (EM: line broadening factor [Hz]; PR2: coefficients used for windowing functions WDW2. 


\begin{tabular}{|c|c|c|c|c|c|c|c|}
\hline $\boldsymbol{\delta}\left({ }^{\mathbf{1}} \mathbf{H}\right)$ [ppm] & $\mathbf{1 0}-\mathbf{7 . 0}$ & $\mathbf{7 . 0}-\mathbf{5 . 3}$ & $\mathbf{4 . 9}-\mathbf{3 . 1}$ & $\mathbf{3 . 1} \mathbf{- 1 . 9}$ & $\mathbf{1 . 9} \mathbf{- 0 . 0}$ & $\begin{array}{c}\mathrm{H}_{\text {olefinic }} / \\
\mathrm{H}_{\text {aromatic }}\end{array}$ & $\begin{array}{c}\mathbf{1 0}-\mathbf{5 . 3} \\
\left(\underline{\mathbf{H}}_{\mathrm{sp}}{ }^{2}\right.\end{array}$ \\
\hline key substructures & $\underline{\mathbf{H}}_{\mathrm{ar}}$ & $\underline{\mathbf{H}} \mathrm{C}=\mathrm{C}, \underline{\mathbf{H} C \mathrm{CO}_{2}}$ & $\underline{\mathbf{H} C O}$ & $\underline{\mathbf{H} C-N,} \underline{\mathbf{H} C-C-X}$ & $\underline{\mathbf{H} C-C-C-}$ & & \\
\hline before $\mathrm{Cl}$ & 2.4 & 2.1 & 19.2 & 28.7 & 47.6 & 0.9 & 4.5 \\
\hline after $\mathrm{Cl}$ & 3.0 & 2.7 & 19.3 & 29.1 & 46.0 & 0.9 & 5.7 \\
\hline
\end{tabular}

Table S2: ${ }^{1} \mathrm{H}$ NMR section integrals (percent of non-exchangeable protons) and key substructures of DOM before and after chlorination. 


\begin{tabular}{|c|c|c|c|c|c|c|c|c|c|c|}
\hline$\delta\left({ }^{13} \mathrm{C}\right) \mathrm{ppm}$ & 220-187 & \multicolumn{2}{|c|}{$187-167$} & $167-145$ & $145-108$ & 108-90 & $90-47$ & $47-0$ & $\begin{array}{l}\mathrm{H} / \mathrm{C} \\
\text { ratio }\end{array}$ & $\begin{array}{l}\mathrm{O} / \mathrm{C} \\
\text { ratio }\end{array}$ \\
\hline Key substructures & $\mathbf{C}=\mathrm{O}$ & \multicolumn{2}{|c|}{ COX } & $\mathrm{C}_{\mathrm{ar}}-\mathrm{O}$ & $\mathbf{C}_{\mathrm{ar}}-\mathrm{C}, \mathrm{H}$ & $\mathrm{O}_{2} \mathrm{CH}$ & $\mathrm{OCH}$ & $\mathrm{CCH}$ & & \\
\hline before chlorination & 1.8 & \multicolumn{2}{|c|}{9.8} & 3.9 & 8.4 & 5.6 & 33.7 & 36.8 & 1.31 & 0.70 \\
\hline after chlorination & 1.7 & \multicolumn{2}{|c|}{9.1} & 3.8 & 10.8 & 5.6 & 32.1 & 35.5 & 1.28 & 0.67 \\
\hline $\begin{array}{c}\text { NMR mixing } \\
\text { model }\end{array}$ & $C=O$ & \multicolumn{2}{|c|}{$\mathrm{COOH}$} & $\mathrm{C}_{\mathrm{ar}}-\mathrm{O}$ & $\mathrm{C}_{\mathrm{ar}}-\mathrm{H}$ & $\mathrm{O}_{2} \mathrm{CH}$ & OCH & $\mathrm{CH}_{2}$ & & \\
\hline H/C ratio & $\mathbf{0}$ & \multicolumn{2}{|c|}{1} & $\mathbf{0}$ & 1 & 1 & 1 & 2 & & \\
\hline $\mathrm{O} / \mathrm{C}$ ratio & 1 & \multicolumn{2}{|c|}{2} & 1 & $\mathbf{0}$ & 2 & 1 & $\mathbf{0}$ & & \\
\hline DOM (depth) & $\begin{array}{c}\mathrm{CH} \\
\text { total }\end{array}$ & $\begin{array}{l}\mathrm{CH}_{2} \\
\text { total }\end{array}$ & $\begin{array}{l}\mathrm{CH}_{3} \\
\text { total }\end{array}$ & \multicolumn{3}{|c|}{$\begin{array}{c}\text { ratio }\left(d_{1} / c_{1} / b_{1} / a_{1}\right) \\
\text { IC } \underline{C}_{a r}-\mathrm{C} / \mathrm{O}-\mathrm{H} \underline{C}-\mathrm{O} / \mathrm{H} \underline{\mathrm{C}}-\mathrm{O} / \mathrm{H} \underline{\mathrm{C}}-\mathrm{C}\end{array}$} & \multicolumn{2}{|c|}{$\begin{array}{c}\text { ratio }\left(\mathbf{b}_{2} / \mathbf{a}_{2}\right) \\
\mathrm{H}_{2} \mathrm{C}-\mathrm{O} / \mathrm{H}_{2} \mathrm{C}-\mathrm{C}\end{array}$} & \multicolumn{2}{|c|}{$\begin{array}{c}\text { ratio }\left(\mathbf{b}_{3} / \mathbf{a}_{3}\right) \\
\mathrm{H}_{3} \underline{\mathrm{C}}-\mathrm{O} / \mathrm{H}_{3} \underline{\mathrm{C}}-\mathrm{C}\end{array}$} \\
\hline before chlorination & 36 & 30 & 34 & \multicolumn{3}{|c|}{15.9 / $1.0 / 33.9 / 49.1$} & \multicolumn{2}{|c|}{6.8 / 93.2} & \multicolumn{2}{|c|}{$9.1 / 90.9$} \\
\hline after chlorination & 35 & 33 & 32 & \multicolumn{3}{|c|}{14.8 / 1.4 / 34.5 / 49.3} & \multicolumn{2}{|c|}{$10.7 / 89.3$} & \multicolumn{2}{|c|}{$5.7 / 94.3^{*}$} \\
\hline
\end{tabular}

Table S3. (Top): ${ }^{13} \mathrm{C}$ NMR section integrals (percent of total carbon) and key substructures of DOM before and after chlorination. Middle: Substructures used for NMR-derived reverse mixing model with nominal $\mathrm{H} / \mathrm{C}$ and $\mathrm{O} / \mathrm{C}$ ratios given. Bottom: percentage of methin, methylene and methyl carbon related to total protonated ${ }^{13} \mathrm{C}$ NMR integral as derived from ${ }^{13} \mathrm{C}$ DEPT NMR spectra of DOM according to carbon multiplicity (left 3 columns) and relative proportions of these $\mathrm{CH}_{\mathrm{n}}$ units binding to oxygen versus carbon chemical environments. 


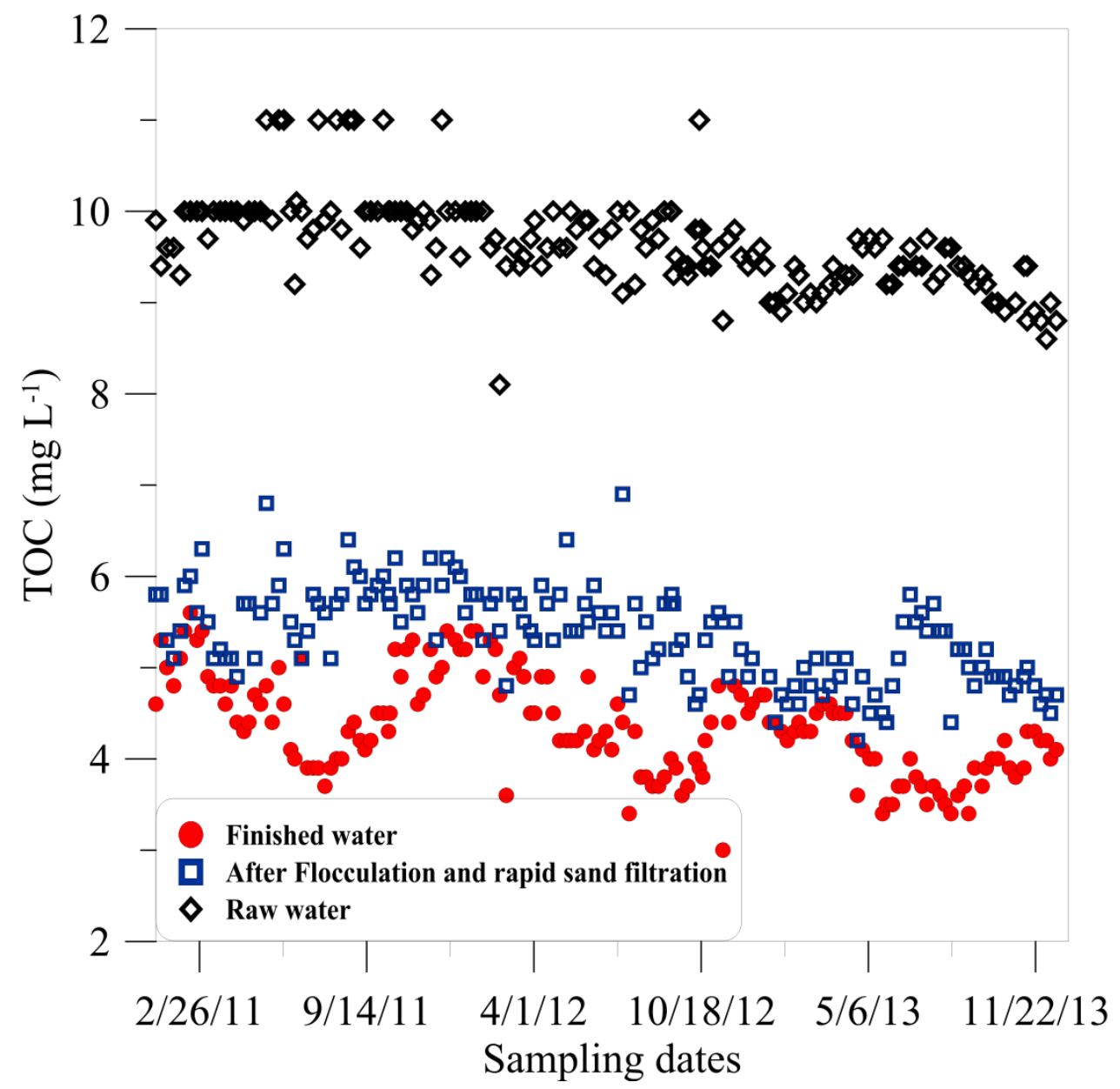

Figure S1: Total organic carbon concentration of the raw water, after flocculation/rapid sand filtration, and of the processed water, Råberga drinking water treatment plant, Linköping, Sweden. 


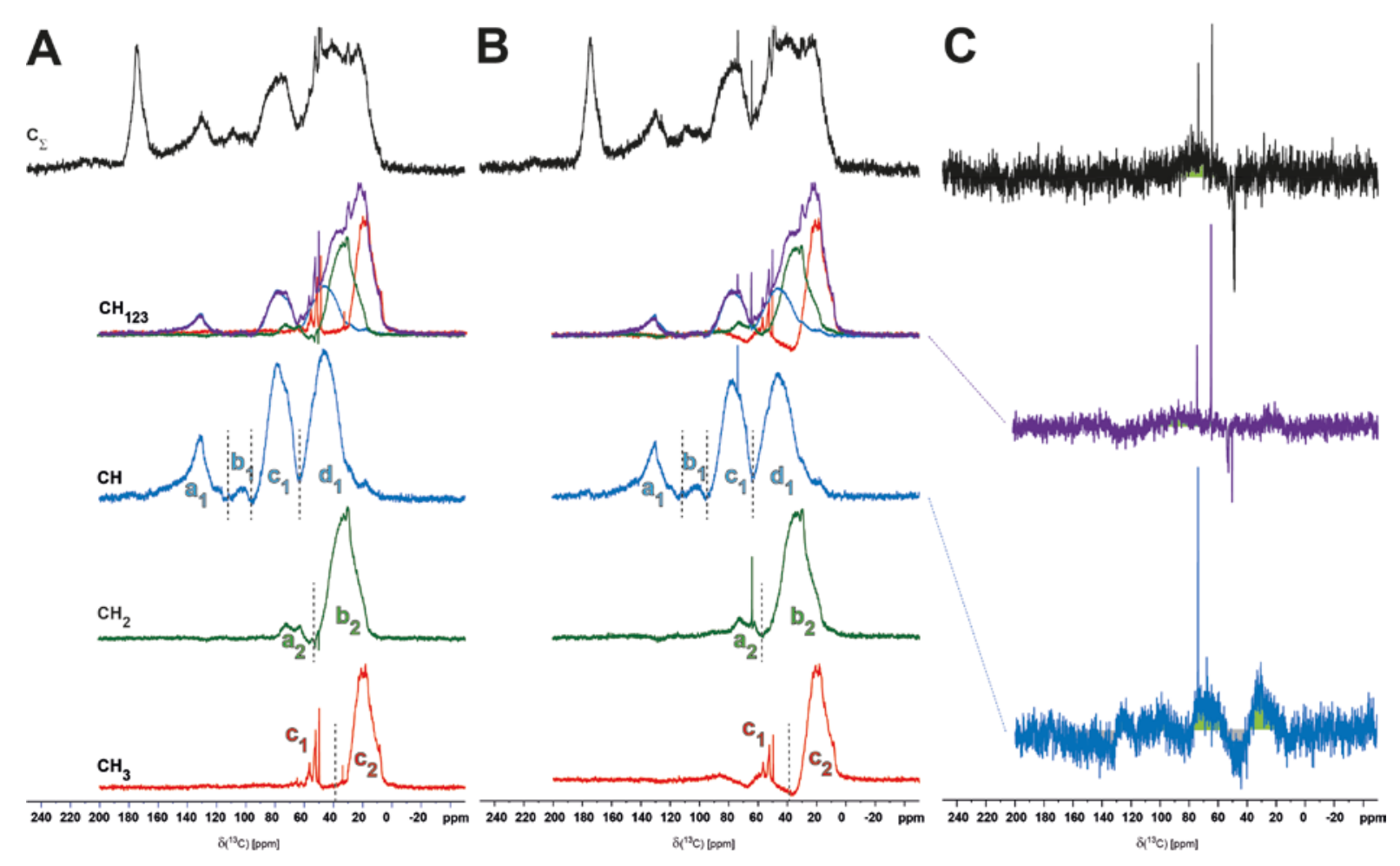

Figure S2: ${ }^{13} \mathrm{C}$ NMR spectra of Raberga slow sand SPE-DOM $\left({ }^{12} \mathrm{CD}_{3} \mathrm{OD}\right.$ solution, $\left.\mathrm{B}_{0}=11.7 \mathrm{~T}\right)$ obtained by solid phase extraction (PPL) before $(\mathbf{A})$ and after $(\mathbf{B})$ chlorination; ${ }^{13} \mathrm{C}$ DEPT NMR spectra: (top) superimposed protonated carbon NMR resonances $\left(\mathrm{CH}_{123}\right.$; DEPT-45 ${ }^{13} \mathrm{C}$ NMR spectra), multiplicity-edited ${ }^{13} \mathrm{C}$ NMR spectra are (second from top) $\mathrm{CH}$; methin, with indices $\mathrm{a}_{1^{-}}$ $\mathrm{d}_{1}$ denoting following chemical environments: $\underline{\mathrm{C}}_{\mathbf{a r}}-\mathrm{C} / \mathrm{O}-\mathrm{H} \underline{\mathbf{C}}-\mathrm{O} / \mathrm{H} \underline{\mathbf{C}}-\mathrm{O} / \mathrm{H} \underline{\mathbf{C}}-\mathrm{C}$ ), (second from bottom) $\mathrm{CH}_{2}$; methylene, with indices $\mathrm{a}_{2}$ and $\mathrm{b}_{2}$ denoting following chemical environments: $\mathrm{H}_{2} \underline{\mathbf{C}}-\mathrm{O} / \mathrm{H}_{2} \underline{\mathbf{C}}-\mathbf{C}$, and (bottom) $\mathrm{CH}_{3}$; methyl, with indices $\mathrm{a}_{3}$ and $\mathrm{b}_{3}$ denoting following chemical environments : $\mathrm{H}_{3} \underline{\mathbf{C}}-\mathrm{O} / \mathrm{H}_{3} \underline{\mathbf{C}}-\mathrm{C}$. The respective ${ }^{13} \mathrm{C}$ NMR section integrals are provided in Tab. 4. (C) difference ${ }^{13} \mathrm{C}$ NMR spectra as derived from (top) single pulse ${ }^{13} \mathrm{C}$ NMR spectra, (middle) DEPT-45 ${ }^{13} \mathrm{C}$ NMR spectra, and (bottom) DEPT-90 ${ }^{13} \mathrm{C}$ NMR spectra. 